\title{
LEPROSY CONTROL IN TRINIDAD
}

E. MUIR

(Reprinted from Caribbean Medical Journal, Vol. IV, No. 3, 1942, p. 83.)

Leprosy cannot be regarded as one of the major diseases in Trinidad, that is to say, it is not comparable in morbidity and mortality with such conditions as malaria, tuberculosis. venereal diseases, ankylostomiasis and malnutrition. The number of cases is probably not great: a rough estimate might place them at about a thousand, though it is difficult to form any accurate idea because of the tendency towards conceal. ment. The mortality is not high; but mortality is not a true criterion of the seriousness of leprosy, which is far more dreaded than other fatal diseases.

There are three main reasons for treating leprosy more seriously and giving it more attention than its low morbidity and mortality would seem to warrant: (a) it is regarded with great dread by the public; (b) given the necessary support by 
the health authorities and the medical profession, it could be controlled and cradicated in a comparatively short time; and (c) the public health measures which are advocated in this paper for the control of leprosy have considerabe collateral value in the control of other diseases.

Until recently, little was done to control leprosy beyond segregation in Chacachacare of those patients who either voluntarily presented themselves or were detected from time to time by physicians in their practice. Thus only the more obvious caseš were brought in, and many of them had previous to their isolation been potential spreaders of the disease for long periods. Not infrequently, under a mistaken diagnosis, subjects of leprosy have been treated as suffering from syphilis and other diseases, and the earlier or less severe cases havt escaped detection or been diagnosed as those of ringworm, psoriasis or similar skin diseases. For these mistakes in diagnosis I do not blame the medical profession. It is only: recently that leprosy has become recognised as a remediabic disease, and those who have qualified as doctors in Britain or America, and even those who have taken the Diploma of Tropical Medicine, have had scant facilities for becoming acquainted with the appearance and nature of leprosy.

Medical Education. One of the first steps in the can' paign against lepros' $y^{\prime}$ was therefore the carrying out of an educational programme. Courses attended by most of the doctors in the Colony were held in Port of Spain and San Fernando. The Medical Officers of Health are each in turn spending three or more months at Chacachacare so as to undergo a period of intensive study of leprosy. Other physicians have expressed a desire for similar intensive study, and it is hoped that arrangements may be made for this late . $_{\text {. }}$ A series of five articles was published in the Caribbean Medical Journal. Short courses of intensive study have been arranged for sanitary inspectors and public health nurses, dentists and others.

Public Education. Iarge numbers of public meetings are being held with the object of educating the public, and articles have been published in the lay press. The public meetings have been held chiefly in schools, and have been, on the whole, well attended. Generally an opportunity for asking questions is given at these meetings, and the discussions raised have shown the great interest taken by the intelligent public.

It is questionable if there is any other important disease 
about which the public have so many and such serious misconceptions as they have about leprosy. Almost invariably great surprise is expressed, even by well-educated citizens, on being told that leprosy is a contagious and not a hereditary disease. Even more surprise is shown on hearing that a large portion of early cases will speedily yield to treatment. A great deal of confusion exists as to how leprosy is transmitted, and the idea that some cases are infectious and others not, and especially that crippled and deformed cases are not as a rule the most dangerous disease-spreaders, excites a good deal of astonishment.

The education of the public is thus a most important item in the campaign against leprosy.

Frequency of Leprosy. I understand that up to last year no attempt had been made to estimate the amount of leprosy in the Colony. Notification is compulsory according to the I9I 5 Lepers Ordinance. But it is not difficult to escape detec. tion and there is strong inducement to attempt to do so, as both the leper himself and also his family are looked upon as tainted and shunned hy the public. Moreover, up to a certain stage, lepros $y^{r}$ is not difficult to conceal; and those admitted to Chacachacare have often reached a stage which shows that they have been potential spreaders of the disease for years before admission. It seemed clear therefore that the system in vogue was not likely to control or abolish leprosy in the Colony, and that if an advance was to be made it would be necessary to find out and control the infection-spreaders who were at large.

It has been the experience in other countries that in proportion as force and compulsion are used in carrying out a survey the attempt is rendered ineffective by driving to concealment. A certain amount of compulsion has to be used, but the bad effects of compulsion should be cancelled as far as possible by the education of the community and by attracting. patients to come forward voluntarily in the early stages in the hope of recovery through treatment. The triple Propaganda. Treatment-Survey system (P.T.S. for short) was first used in India, and has been adopted in other countries with equal success, notably in British Guiana. Under this method the public is enlightened regarding the nature of leprosy, treatment is offered in as attractive a form as possible, and as confidence and enlightenment are thus gained a survey is gradually completed. 
In Trinidad there are certain difficulties in utilizing this system.

I. The fear of the ostracism connected with leprosy tends to concealment. In India and Africa, where people wear few clothes, and where people remain in one village all their lives, leorosy is more difficult to conceal. But in Trinidad, where the whole body except the face and hands is covered with clothing, it is not difficult to hide the disease during the earlier stares. The clinical signs of the open lepromatous type are often masked for years; and leprosy, apart from a careful clinical inspection and bacteriological examination, $w$ uld pass unnoticed even by an expert doctor. Such patients are potential spreaders of infection both in their own households and among those with whom they come in contact at work or when travelling in public vehicles.

2. People in Trinidad tend to. travel from one place to another and frequently shift their place of residence. Thus, even if they are suspected of leprosy in one town or village, they can escape suspicion in their new abode.

3. The dearth of labour in this island makes it easy to get work without employers insisting on careful medical examination or without their enquiring into references or the precedents of their employees. Thus patients not infrequently abscond from Chacachacare and find work in the American Bases, the oilfields or elsewhere.

4: The public of Trinidad have not yet become what is styled "leprosy conscious"; they know little about the appearance of leprosy. Even doctors not infrequently miss cases which have passed beyond the earlier stages.

5. The common early neural lesions of leprosy are not likelv to be spotted unless they happen to be located on the unclothed parts of the body. In making examinations of schoolchildren I have frequently found such lesions, and doctors and nurses who have not undergone a special course of leprosv have been astonished when I made a diagnosis of leprosy, supposing the leprides to be snme form of ringworm or other less serious skin disease.

Methods of Survey used. In India leprosv is a very common disease. It is estimated that there are from one to one and a half million sufferers from the disease, making an average of about three or four per mile. But the distribution is not by any means equal, and in manv places it rises to as much as 3 per cent. of the population. The method used there in carrying out a survey is to institute a leprosy clinic. Soon 
many cases are gathered together voluntarily for treatment. These people are followed up to thcir village, contacts are examined, and then the survey is gradually completed. At the same time instruction is given as to the nature of leprosy and the precautions that have to be made to prevent its spread. Thus in the course of months or years people gradually become "leprosy conscious." In the province of Madras alone there are at present more than 450 leprosy clinics.

In Trinidad leprosy is not nearly so common, and the P.T.S. method has to be adapted to local conditions. The chief reliance has been laid on the examination of schools. Up to the 22nd of May, 1942, I had examined i 78 schools and found 83 cases of leprosy distributed as follows:

\begin{tabular}{|c|c|c|c|c|c|}
\hline & $\begin{array}{c}\text { Nun } \\
\text { hools }\end{array}$ & $\begin{array}{l}\text { nher of } \\
\text { examined. }\end{array}$ & $\begin{array}{l}\text { Number } \\
\text { ast Indians. }\end{array}$ & $\begin{array}{l}\text { f cases found. } \\
\text { fricans. }\end{array}$ & \\
\hline t. Patrick County & $\ldots$ & 23 & 3 & 20 & 23 \\
\hline San Fernando & $\ldots$ & 8 & 5 & 8 & 13 \\
\hline Victoria County & $\ldots$ & 44 & 3 & 6 & 9 \\
\hline Caroni & $\ldots$ & 36 & I 3 & I 4 & 27 \\
\hline Tobago & $\ldots$ & 33 & 0 & I & 1 \\
\hline St. David County & $\ldots$ & IO & 0 & 0 & \\
\hline t. Andrew Coun & nty & 12 & 0 & I & \\
\hline Arima (town and rur & ral) & II & I & 5 & \\
\hline t. Joseph .. & $\ldots$ & I & o & 3 & 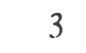 \\
\hline & otal & I 78 & $25(30 \%)$ & $58(70 \%)$ & 8 \\
\hline
\end{tabular}

It will be noticed that $70 \%$ of the cases discovered are African (two of these were of mixed European and African origin), and onlv $30 \%$ East Indians. Onlv in Caroni Countv does the number of Indians approach that of the Africans affected.

This is contrary to the commonly held idea that leprosy is more common among Indians. Even allowing that there may be twice as manv Africans in the Colony as there are of Indians, these figures still show a higher proportionate incidence in the former.

The school examinations were not by any means exhaustive. Often nearly half the children were absent. Not infrequently one finds that several of the children present abscond when they see the doctor, either from fear engendered by their experience of previous visitors who have come to give injections, or, possibly in some cases, because they know or suspect that they have leprosy and have been told by their parents to avoid medical inspection. 
Not infrequently the follow-11) of cases discovered in schools had led to discovery of the disease among contacts. Thus the investigation of the contacts of one girl showed up five other cases, and those of one hoy showed up eight others.

So far I have found only one open or infectious casc in the schools. Most of them showed tuberculoid or simple. leprides of the neural type.

I have not yet had time to examine the schools in what appears, judging by the number of leprous patients it sends to Chacachacare, to be the most leprous part of the Colony, that is Port of Spain and the region along the Eastern Road.

Particularly striking was the infrequency of leprosy in the island of Tobago. . Before making the survey there I examined the seven cases from Tohago at present in Chacachacare. From the records it appeared that all of them had had ample opportunities for acquiring the disease either in the island of Trinidad or in other endemic countries. In the thirty-three schools examined no leprosy was found except for a tuberculoid patch of the size of a shilling on one little girl. On enquiry she turned out to he the niece of one of the cases in Chacachacare. The same infrequency of leprosy was found in the St. David and St. Andrew Counties. In St. David no leprosy was found. In St. Andrew only in one scheol was a case found, a bov whose cousin was a former Chacarhacare patient who had heen discharged some years before and is now working in the American Base at Cumuto. This boy had arrived only recently from San Juan, where there is reason to helieve that the incidence of leprosy is comparatively high. Examination of records showed that the number of lepers admitted from St. David and St. Andrew is very low, and I failed to find more than one other case.

The low incidence of leprosy in Tohago, St. David and St. Andrew, as compared with that in such places as Port of Spain, the Eastern Road, San Fernando, Princes Town and Caroni County, makes an interesting study. It is particularly interesting to find seven lepers from Tobago, most of them lepromatous open cases, admitted to and now resident at Chacachacare; and yet, with one slight exception, not a sinole case to be found, as far as investigation went, at present on the island. This confirms the idea that these seven lepers acquired the disease abroad and not in Tobago; and that hecause of the present conditions in that island they were quickly detected and sent away for segregation. Those of you who are familiar with Tohago know that the conditions there 
are what may be described as primitive and the people unsophisticated. Compared with I rimsdad there is little industrialism, people remain in their viliage and hamlets and are well known to one another and consequently to the doctors. Leprosy being an exotic disease imported from outside, is likely, because of its unusual appearance, to become known to the health authorities. It thus has litcle chance of being spread; the potencial spreadis are quickly spotted and seni away tor segregation. Although the average population per square mile 1s, or was till iately, higher in I obago than 11 Trmidad, yec the people are more evenly spread, and there is less crowding and consequenily less chance of infection. The same applies also to the Counties of St. David and St. Andrew.

In Trinidad, on the other hand, and especially in the industrialised areas I have inentioned, the people are constantly moving from one place to another and are little known to one another. Rents are high and there is much more crowding together. These two factors, the shifting of population and overcrowding are perhaps the most important in the distribution of the disease.

It is also interesting to note that signs of malnutrition are as a rule more comiion in children in industrial than in rural areas. In the former there may be more money, but the children, especially the younger ones, are more neglected; whereas the people in the rural areas, such as Tobago, St. David and St. Andrew, though poorer, have their own culti vation plots and look after the young children better. It is generaily agreed that malnutrition is an important predisposing factor in leprosy, and this may partly account for the greater frequency of leprosy in the industrial areas.

How long Tobago and other rural areas will remain comparatively free from lepros $y^{\prime}$ is difficult to say, for in recent years and especially in the last twelve months much more movement of population has begun, the young men seeking employment in the oilfields and especially in the American Bases.

Health Services and leprosy. In the control of leprosy in Trinidad the health services will necessarily play the most important part. I wish to acknowledge the splendid work done by the Medical Officers of Health who have studied leprosy at Chacachacare. Considerable assistance has also been given by some of the District Medical Officers. In this work I have also been helped by the Sanitary Inspectors and Health Nurses who 
have accompanied me in examining the schools and have themselves detected cases among adults. Most of the Health Nurses have attended courses in Chacachacare and it is hoped to complete the courses of training of the Sanitary Inspectors before the end of July.

I hope to finish the first rough survey of Trinidad and Tobago by the end of this year; but a surve $y^{\prime}$ of this kind will in itself be of little value in controlling leprosy. A complete survey can only be gradually completed throughout a series of years; and this must necessarily be done through the machiner, of those constantly on the spot, that is by the M.O.H.'s, D.M.O.'s, Sanitary Inspectors and Healch Nurses. My chief object in my rough survey is to set the machinery in motion.

Leprosy Clinics. The idea that many cases are non. infectious and are suitable for out-patient treatment is a new one in Trindad. In St. Patrick's County the M.O.H. has for the last year been treating such cases successfully in their own homes, while in San Fernando and Couva the M.O.H.'s have been treating them in special clinics held every week. It is remarkable to see the look of relief on a parent's face, when I tell him that his child will not have to leave home and go " down to the islands," but will be treated locally. They are also told that if they do not attend regularly the disease may .get worse, and then they may have to leave home. The fear of this possible eventuality is generally sufficient to secure regular attendance.

I hope that by the time the first survey is completed satisfactory arrangements for the out-patient treatment of all suitable cases will have been made.

Leprosy Board. The study of leprosy in Trindad makes it clear that there should be a "Leprosy Board" which will be responsible for the co-ordination and thorough carrying out of the campaign against leprosy throughout the Colony. One of the duties of this Board would be to compile-a complete, confidential list of all those who have, or have had, leprosy. This list would be kept up to date,' and, as far as possible, all possible sources of infection would be mapped out.

The Board would also see that there were facilities for outpatient treatment of all those who could be thus suitably treated and that attendances for treatment were regular. There would be a special list of .all absconders from Chacachacare and arrangements would be made for seeking out such persons and seeing that they were sent back. 
In the past there has not been a satisfactory follow-up of "discharges" from the Leprosarium. During the last 18 months many of these have been readmitted in a condition which showed that after their discharge they had relapsed and had then been for some years potential spreaders of the disease. It would be one of the duties of the Leprosy Board to go through past records, find as many of these discharged cases as possible and see that there was satisfactory three-monthly inspection of all discharged cases.

l.eper Ordinance. The present Ordinance and Rules were passed in 1915, and, as much advance has taken place in our knowledge of leprosy since then, they are now in many respects quite out of date. It is hoped to have them revised in the near future and brought into line with our present knowledge of the nature of leprosy and the best means for its control. This is a matter which I have in hand at present.

Lastly, I wish to appeal to the Medical Profession in this Colony as represented by you to help in the campaign against leprosy. Many of you have already given me very considerable help and encouragement in the last 18 months, and I feel sure that with your full assistance it will be possible in the course of a few years gradually to bring this disease under control.

P'aper read at a meeting of the Northern Section ol the Trinidad and Tobago Branch of the B.M.A., and published with the consent of the Director of Medical Services. 